\title{
On the Economic Approach to Bilingual Education in China
}

\author{
Zhiwei Xiong \\ School of intercultural Studies, Jiangxi Normal University \\ 99 Zi yang Street, Nanchang 330022, Jiangxi Province, China \\ Tel: 86-791-601-3946Ｅ-mail: lightinair@163.com \\ Cheng Shao \\ Department of Business and trade, Jiangxi BlueSky University \\ Beijing East Street 1118, Nanchang 330029, Jiangxi Province, China \\ E-mail: shaocheng1213@sina.com
}

\begin{abstract}
In the process of globalization, each country culture retains an independence from the others besides in reality a fusion of several cultures. Bilingual education as an effective means and intangible resource, which have long been neglected, will play an important part in social and economic development in China.

Bilingual education, in this method of language instruction, the regular school curriculum is taught through the medium of a foreign/second language. The foreign/second language is the vehicle for content instruction. The subject of the instruction is to make students master language as well as subject knowledge.

This thesis attempts to expound the necessity of the implementation of bilingual education in China in the process of globalization. Bilingual education is mot a unitary language phenomenon and usually displays an essentially economic concern for the languages to be used. Hence, economics can be of service and offer insights and information in the study of language issues that other approaches do not provide so far. besides, the problems in China's bilingual education are analyzed, followed by a list of suggestions for reference, however, due to a variety of reasons ,there still exist several drawbacks like lack of linear research and whatnot. Those are to be dealt with in further researches.
\end{abstract}

Keywords: Globalization, Bilingual education, Economics, Problems

With globalization process and the rapid social and economic development, the need for bilingual talents is ever-increasing. In response, China has begun a new educational reform ----Chinese-English bilingual education. There has witnessed a rapid growth of bilingual schools and classes. However, due to lack of theoretical and practical research, there are a couple of problems which deserve attention, for instance, the shortage of bilingual teachers and materials and the absence of bilingual environment.

Learning a language in wider communication not only can yield benefit to an individual but also add to the benefits of all other members. This generates the economics of language, or language economics, an emerging field of research that is taking an increasing interest in the economic aspects of language matters. Its aim is to provide readers, particularly non-economists, a clear idea of what economics could say about language matters (Grin 1996). Over the past 40 years, the applying of the principles of economic modeling to language issues has shed new light on the explanation of the production and consumption of a language and its effect on the national economy. Indeed, language cannot be adequately studied without being given full consideration to its economic aspect.

This thesis will make reference to the insights of early studies in the economics of language and use some of the mainstream economic theoretical framework to evaluate the cause-and-effect sequence of language issues, especially, language education in China. Chapter two presents a brief review of globalization, Chapter three and four introduces the economic analysis of bilingual education and the costs and benefits of bilingualism in China .Chapter five presents what are the necessary support ways to improve the bilingual education?

\section{Globalization and new linguistic order}

\subsection{Definitions of globalization}

Wherever in the west or the east, has the globalization become a hot topic, just like the KFC. Jan Art Scholte (2000) has argued that at least five broad definitions of globalizations can be found in the literature. Globalization as internationalization regards globalization as simply another adjective to describe cross border relations between countries .it descries the growth in international exchange and interdependence. Globalization as liberalization refers to 
a process of removing government-imposed restrictions on movements between countries in order to create an open, borderless world economy. Globalization as universalization means the process of spreading various objects and experiences to people at all corners of the earth. Globalization as westernization or modernization is understood as a dynamic, whereby the social structures of modernity are spread the world over, normally destroying pre-existent cultures and local self-determination in the process.

\subsection{The new linguistic order-Bilingualism}

There has never been a time when so many nations need talk to each other so much. There has never been a time when so many people wished to travel to so many places. And never has there been a more urgent need for a global language (Crystal, 1997).However, the spread of English as a global language has not lessened the importance of local language development. Languages of identity need to be maintained. Arguments about the need for national or cultural identity are often seen as being opposed to those about the need for mutual intelligibility. According to Crystal (1997), this situation is the familiar one of bilingualism ---but bilingualism where one of the languages within a speaker is the global language, providing access to the world community and the other is a regional language, providing access to a local community. The two functions can be seen as complementary, responding to different needs. No two languages will compete for the same function, so a world of linguistic diversity can in principle continue to exist in a world united by a common language

\subsection{What is bilingualism and bilingual education?}

What is bilingualism? According to $<<$ Oxford Advanced Learner's Dictionary of Current English with Chinese Translation $>>$, a person who speaks two languages is called bilingual. The bilingual does not have to speak both languages with equal fluency to be a bilingual. It is very common for bilinguals, even those who have been bilingual since birth, to be somewhat dominant in one language. We define bilingual simply as using two languages on a regular basis.

What Is Bilingual Education? The definition of bilingual education in $<<$ Longmen Linguistics Dictionary $>>$ is that "education system that uses a second or foreign language as the instructional language in school". Skutnabb-kangas (1978) the world's famous expert of bilingual education, pointed out that bilingual education is the education system with two languages as its instructional language, one of them is usually the students' first language, but not utterly is. Derek Rowntree (1976) Educationalist in UK said bilingual education is the education that aims to cultivate the students' ability to use two languages equally. Each language takes up half amount of instructional language.

\subsection{Bilingual education abroad}

\subsubsection{America}

Aimed at enabling students with different mother tongues to master English, The Bilingual Education Act, passed by the Congress in 1968, was implemented independently in each state with the specific situation of each state taken into account. After years of bilingual education, there showed some doubts about it, for example, in the bilingual school the immigrants were argued to give up mother tongue because they must learn English well as long as they want to live in America, but some opponents argue that giving up mother tongue and mother culture will do harm to child immigrants and affect the learning of both English and mother tongue when a student with limited English proficiency studies in an all-English environment. De la pena (1991) reports that he went to the USA at 9 with no English proficiency and claims that he succeeded without bilingual education. Currently, disputes are still hot and bilingual education is facing a grim challenge in America.

\subsubsection{Singapore}

Unlike America, Singapore is quite successful in bilingual education. There are few disputes. Bilingual education plays an important role in this country's development. it helping Singapore maintain its unique national features. Singapore's bilingual education possesses the following five features: strong government support; early bilingual education starting from children; adoption of an individualized teaching; a positive bilingual environment and the ready parental support.

Like America, Singapore also has problems in practice. One problem is that the bilingual education tends to lay more emphasis on English than on mother tongue, students turning to favor English and their English proficiency is remarkably higher than mother tongue proficiency. This may pose a threat to the preservation of national language and culture.

\section{The economic approach to bilingual education}

\subsection{Costs and benefits analysis}

Previous product of research into links between bilingualism and the economy is framed by an understanding of language as an ingredient of human capital; within the economic framework of costs and benefits, supply and demand, investment and yield (Breton 1978) bilingual education, especially, the second language learning and teaching has 
received little attention in the economics of language and in the economics of education. There is little theoretical or empirical work on the costs and benefits of the second language learning. A proper understanding of the economic aspects of bilingual education is to relate the second language with the economic activities in line of the costs and benefits of individuals as well as the nations.

To the economist, every choice involves an opportunity cost-the benefit expected from value of sources in their next best alternative use. The object of cost-benefit analysis is to give a true picture of the probable consequences in evaluation those that are judge to be essential from an economic, social point of view. One popular method of evaluating bilingual education is to relate costs of bilingual education to the benefit to be derived.

\subsection{Costs}

Generally, the government plays a pivotal role in shaping the scope and form of investments in bilingual education. The costs on the government promotion of bilingual education may be measured by the linguistic similarity level of the first and the second language, the number of competent teachers. And, especially, on the degree of bilingualism of the society .I think the linguistic similarity may be the most influencing one.

The more linguistically similar the languages, the lower the costs of bilingual education because the structural closeness of languages to each other have often been thought to be an important factor in foreign language learning.

There exists a severe shortage of bilingual teachers both skillful in instruction languages and specific content areas, and institutions in most countries, and the more closeness the target language to the native language, the lower will be the training cost. By the way, the demand for bilingual teachers will lead to the salary increase of bilingual teachers, and thus increase bilingual cost in public.

For the society and individuals, bilingual education costs time and tuitions, but the promoted target language is hardly heard or seldom used, bilingual education could be very expensive and the outputs may be very low.

\subsection{Benefits}

\subsubsection{Individual benefits}

For individuals, if someone decides to invest in the learning of a second language, she will no doubt derive return from bilingual education. We first turn our attention to the communicative benefit of language learning. Obviously, ideas and technical information will flow more easily if there is no language barrier. Despite the communicative benefit, there is also the occupation benefit. For example, if you can speak a second language, then maybe you can get a job at the national level than the factory workers or laborers who are able to work in isolation with members of their own language groups.

Direct benefits to the individual are typically measured by the increased earning power that an individual derives from knowing two languages after his completion of the bilingual program. For example, in a survey of the reward of English language skills on the Swiss labor market, the computation of average labor income by level of English language skills reveals a strong positive correlation. The reason is that English language skills are correlated with other determinants of income, particularly education, and that higher earnings accruing to those who speak English may simply reflect the fact that having a higher education, they can hold better-paying jobs.

Despite of the direct economic benefit from trading with individuals of a different language group, individuals also get benefit from broadening his experience in learning about the people of a different background that is cultural benefit. It will affect the ways you thinking when you facing the problems and solving the problems better.

\subsubsection{Social benefits}

Try to imagine, in a country the ability of citizens to speak more than one language will bring much more opportunities for international trade and tourism. To this extent, bilingualism increases the opportunities for exports and imports for foreign trade compared to unilingualism. And if communication barriers are decreased, then labor services will be freed for work in production. So, the decrease in the language barrier will increase in the effective labor force of the country , and as a result of the improvement in communications and the decrease in transaction costs, the return to capital will rise(Breton and Mieszkowski,1997)

In a word, are the benefits from bilingual education greater than the costs? I think the answer will different from society to society and person to person.

\section{The economic of bilingualism in China}

\subsection{The bilingual education in China}

China has the largest English-learning population in the world, "it seems there are more people learning to speak English in China than there are English speakers in the whole of the United States' (Taylor 2002) After our country entering WTO. We are facing serious challenge of talent competition. At present, China is urgently needs masses of 
high-level, high-quality, and all-around talents. Bilingual education is the demand of our country entering into WTO and enhancing international competition. But due to the lack of experience, China is facing some problems in the novel undertaking of Chinese-English bilingual education. First, the qualified bilingual teachers are in urgent need. This is a most serious problem confronting China. Second, misconceptions about bilingual education exist. Some people simply regarding it as the intensive teaching of English. Third, bilingual teaching materials are to be enriched. The current English teaching materials are compiled with improving English proficiency as its main goal. However, bilingual education needs English books on various subject matters, for example, biology, math, chemistry, etc.

\subsection{Costs and benefits of bilingualism in China}

\subsubsection{Costs of bilingual education in China}

The costs in this discussion are learning costs in nature. Three variables are used in an economic context to merit a brief background discussion:

(1) Bilingual teaching condition

The most English learners in China living in an environment in which the majority communicates in Chinese, the time in English is smaller. Language teaching professions believe that the more time spend learning any aspects of a second language, the more will be learned (Spolsky 1989).

So some experts suggest that bilingual education is most suitable in college, where the students have the basic listening skills to understand the lectures in English, but the fact is that most of the students in college think that using English in class will make the content learning less efficient and cost them an extra effort. And this is not easy even for a teacher that using English in class all the time. Take account the teaching situation in China, training teachers for bilingual teaching is a priority in the implementation of the bilingual education programs. But in China, unfortunately, at least more than half of the existing bilingual teachers ate teaching under waiver strategies that is beneficial neither to subject matter knowledge nor English proficiency.

In order to avoid this kind of situation, the government should embark on a long-term project and assign more resources to teacher's bilingual development. The present problem is that while there is a great need for "well-trained" teachers for bilingual education, we know less about how best to train these teachers. This makes the return of the government investment difficult to be assessed.

(2) Linguistic similarity;

We all know that the learning of English in China is not an easy task. There are many Chinese college graduates could not use English in their daily communication after more than 10 years English learning. One typical example is that most Chinese have difficulties in pronouncing the English consonant. We know English is closer to French than it is to Chinese. So a French -speaker learning English is easier than Chinese. Like Spolsky once said the more linguistically similar the languages, the easier the master the language and the lower the costs of bilingual education, so we can get the following equation:

$\mathrm{COST}=\mathrm{f}$ (teaching input, linguistic distance, linguistic environment)

We can infer from this equation that the bilingual education in China is not an easy task. According to China Statistics Yearbook 2004, though the total GDP 2002 amount to more than 105172.3 billion RMB, the GDP per capita is not more than 1000 USD. Economic incentives can be expected to implement bilingual education but bilingual teaching is far from ready.

\section{(3) Linguistic environment}

We have noted that the majority of Chinese knows only one language and only a minority of the population is bilingual. English in China has not developed uniformly due to a number of social, economic and historic factors. In the cities like Beijing and Shenzhen, English is used extensively to such an extent that there is a few English-speaking community inside these cities, like the English corner. While in other areas, Like Shanghai and Tianjin, local government sponsored English promotion programs and training are at all levels, English graduates hot in the labor market, foreign investment, import and export value in these cities take $73 \%$ of the total investment, the status of English is close to semi-official language and the English level is high enough to contribute to the development of the national economy. In contrast, English level cities like Guizhou and Gansu is much lower. It is said that even the English teachers cannot pronounce English words correctly. In minority areas, such as Tobet, the promotion of Mandarin is still an ongoing issue. It is unlikely that the bilingual teaching will be in spread in these areas.

\subsubsection{Benefits of bilingualism in China}

In recent years, for most foreign funded companies in China operate at the destination of employing Chinese local markets, the need for foreign language skills seems to be quite low. Technical expertise is seen as more important. The very fact that the labor market demand for language-only specials in 2005 almost dropped to zero is a proof. So foreign 
language skills in China do not seem to play an important role in hiring. And so far there does not seem to be much evidence of bilingual benefits in enterprises in China. The reason is that any benefit measured in language may be a product of the person's education attainment rather than language knowledge.

Economic benefits of bilingualism to individuals in China seem to be obscure in the measure of income but appear opaque in the individuals' promotion requirement and future development. Since the reform and opening policy, English has been the most primary tool to absorb foreign technologies in China. Crystal (19970writes that: English is the main language of books, newspapers, airport and air-traffic control. international business and medicine, sports, pop music, and advertising. Over two-thirds of the world's scientists write in English, three quarters of the world's mail I written in English.

The social benefits of bilingualism are more likely to be visible in China. In the rapid developed global economy, English is considered the first necessity for the survival of Chinese society. Bilingual education is the most ideal means to quickly improve the practical English skills among Chinese speakers. Bilingual groups both constitute societies large and dense enough to be able to trade abroad, and contribute to the advancement of knowledge. In this regard, an advanced bilingualism fosters the economic growth and makes China a more appropriate partner for trade on the world market.

The entire value of bilingual education must also be view in light of its social possibilities and consequences. The above economic benefit considered is only the value of bilingual education in China characterized by the demand of market economy. Actually, the market value of bilingual education is not inclusive of all the benefits accruable from bilingualism. In the broader context, benefits include anything which is resulted from bilingualism in increasing social welfare possibilities, such as the development of public-spiritedness and culture consciousness.

A society with advanced bilingualism is thus to be more receptive to different ideas, in a multi ethical country like China, bilingualism is expected to create an increasingly open society that welcomes changes, project a more efficient government and lead to a more vibrant democracy with stronger webs of social affiliation .

Bilingual education in China is a heated controversial issue and will be kept in the limelight of educational debase, it takes a unique position among educational programs. Though there has been much criticism of the implementation of bilingual education, various forms of bilingual education are being widely experimented throughout China. It reflects the need of the individual and the society as a whole.

Obviously, estimated benefits and costs reflect the preferences of individuals. As such as members of social groups. These preferences are socially, culturally and historically determined. In addition to an economic yield to languages, cultural yield related to literary and other forms of creativity is likely to generate considerable benefits for society as a whole.

\section{Ways to improve the efficiency of bilingual education}

\subsection{Training more qualified bilingual teachers}

To make bilingual teaching successful, to train more qualified bilingual teacher is very urgent at present. Universities and colleges, schools and teachers, all of them should work hard towards this end. Normal universities should set up some special courses which are given in English, encourage non-English majors to study English and English majors to learn other courses. As a result, bilingual teachers will be strengthened.

\subsection{Employing many professional foreign teachers}

Considering the lack of qualified bilingual teachers nowadays, professional foreign teachers should be employed. Foreign teachers can speak the most standard oral English and they teach the students in the English environment, students have more opportunities to communicate with foreign teachers in English. Consequently, the students' oral English can be improved.

\subsection{Dividing the students into different classes}

It is obvious that every student's English ability is different. Therefore, when giving a bilingual education, the best way is made them be divided into different classes according their proficiency. Students with good English proficiency can form a class and students with intermediate proficiency can form a class and students with low proficiency can form another class, consequently, bilingual teachers can select different ways for different students. In this way, students of different levels can acquire more knowledge than in mixed class.

\subsection{To develop comprehensive curriculum and learning materials}

The traditional way of teaching that the teachers tell the students what they are to learn, and then ask them to answer questions about what they heard, and always providing the answers themselves if students don't respond quickly enough this limit the learning experience for all students, for it gives them very little opportunity to discuss issues, solve problems, or ask their own questions, and, thus, to develop thinking skills. It is even effect students understanding of 
what the teacher says, and it provides few occasions for students to speak, and practice their English skills.

The lack of books is bilingual education other problem. Original bilingual teaching materials are not available at present because they are costly for most schools and the students. I think, the best way is that teachers or professors can base on the original bilingual teaching materials and then compile the materials which are suitable for our students.

\section{Conclusion}

Nowadays, English has been the chief way of information spread. Bilingual education is the developing requests of the information age. Our country needs the bilingual education especially after China entering WTO. Bilingual education has been widely spread in China, especially those in big cities and it had been done very well in some schools. But the bilingual education in our country's are not mature enough, there are still some problems which impede the development of the bilingual education. Only when these problems are solved, can the bilingual education develop. It is very urgent for all of us to work hard to promote favorable conditions for bilingual education.

This research is not perfect, because of the limited time and my limited knowledge. This research explores the role of bilingual education from the economic cost-benefit analysis of view, aspiring to give a helpful insight into bilingual education in China.

\section{References}

Vaillancourt,Francois. (1982\1983). The economics of language and language planning, Language problems and Language Planning, 7(2), 162-178.

Thorburn, Thomas. (1971). Cost-benefit analysis in language planning, in B.Jernudd and J.Rubin(eds) Can Language Be Planned. Honolulu, University Press of Hawaii, 253-262.

Slavin, R.E. (1988). Cooperative learning and student achievement. In R.E. Slavin (Ed.), school and classroom organization. Hillsdale, NJ: Erlbaum.

Johnson, D.W. \& Johnson, R.T. (1986). Circles of learning: cooperation in the classroom. Edina, MN: interaction book company.

James L. Cooper, Pamela Robinson \& Molly Mckinney. (2001). What is cooperative learning? [Online] Available: http://www.csudh.edu/SOE/cl-network/whatisCL.html (Dec.10.). 